\title{
Studies on the Control of Cylindrocladium buxicola Using Fungicides and Host Resistance
}

\author{
B. Henricot, C. Gorton, G. Denton, and J. Denton, Plant Pathology Department, The Royal Horticultural Society, \\ Wisley, Woking, Surrey, GU23 6QB, UK
}

\begin{abstract}
Henricot, B., Gorton, C., Denton, G., and Denton, J. 2008. Studies on the control of Cylindrocladium buxicola using fungicides and host resistance. Plant Dis. 92:1273-1279.

Cylindrocladium buxicola is a fungal pathogen that causes a severe leaf and twig blight on Buxus spp. Laboratory experiments were carried out to study the in vitro effect of 13 fungicides on mycelial growth and conidia germination of the fungus. Based on the values of the effective concentration at which mycelial growth was inhibited by 50\%, the fungicide Stroby (kresoximmethyl) and the combined fungicides Opponent (epoxiconazole + kresoxim-methyl + pyraclostrobin), Opera (epoxiconazole + pyraclostrobin), and Signum (boscalid + pyraclostrobin) were the most effective at inhibiting mycelial growth and conidia germination. Pathogenicity assays showed that the host range of the fungus was not limited to the genus Buxus because Sarcococca sp. also was susceptible. None of the 10 boxwood species and cultivars tested were immune to the disease, although Buxus balearica as well as Sarcococca sp. showed significantly lower levels of infection as measured by the expression of leaf symptoms and the number of conidia produced on host tissue, the latter probably contributing to the apparent resistance of these species in the field. Microscopic observation showed that disease development was very rapid and aggressive on B. sempervirens 'Suffruticosa' where it was able to survive at least 5 years on decomposing fallen leaves.
\end{abstract}

Additional keywords: Buxaceae, boxwood blight, survival

Cylindrocladium boxwood blight is caused by the fungus Cylindrocladium buxicola Henricot, (13) and was detected in the United Kingdom in the mid-1990s (14). In the last 20 years, boxwood, especially Buxus sempervirens and its cultivar 'Suffruticosa', has become one of the most widely grown plants in the United Kingdom, due mainly to the renaissance of parterres and knot gardens. Until recently, boxwood plants were considered to be generally trouble free. The main diseases recorded before the introduction of $C$. buxicola were twig and leaf blight caused by Volutella buxi, Phytophthora root rot, and rust caused by Puccinia buxi (24). C. buxicola is devastating on Buxus spp., causing severe defoliation and dieback, which can rapidly spread throughout the plant in warm and humid conditions. The disease is now widespread throughout the United Kingdom and causes great concern among boxwood growers. The disease has

Corresponding author: B. Henricot

E-mail: beatricehenricot@rhs.org.uk

Accepted for publication 13 May 2008.

doi:10.1094/PDIS-92-9-1273

(c) 2008 The American Phytopathological Society also been recorded in other European countries, including Belgium in 1998 (The Royal Horticultural Society [RHS] advisory database), Ireland in 2001 (RHS advisory database), Germany in 2005 (6), and Holland in 2005 (Marcel van Raak, personal communication). Outside Europe, $C$. buxicola has only been confirmed in New Zealand (13).

Control measures include cutting back infected twigs to healthy tissue and removing fallen plant material and topsoil. There are no fungicides specifically labeled for the control of the genus Cylindrocladium on Buxus spp. The only fungicides available to amateur gardeners for general use on ornamentals in the United Kingdom are myclobutanil and penconazole; however, there is no information available on their efficacy in controlling boxwood blight. Similarly, there are approved commercial products that can be used on ornamental crops in nurseries but no data are available on their efficacy or the dosage and rate to control the disease on boxwood plants. An important mode of spread has been through the introduction of apparently healthy Buxus material carrying the disease into gardens or nurseries (personal observation). Brasier (7) has referred to this as "the Trojan horse syndrome." Therefore, the aim of this study was to assess the in vitro effectiveness of fungicides available in the amateur market as well as some of the most commonly used fungicides used in commercial boxwood nurseries.

The genus Buxus includes 91 species distributed over four continents, with 10 species occurring in Africa, 45 in America, 34 in Asia, and 2 in Europe (2). To date, the disease has been detected on only several cultivars of three species of Buxus: $B$. sempervirens, $B$. microphylla, and $B$. sinica var. insularis (RHS records). The largest numbers of cultivars (185) have been raised from $B$. sempervirens that is native to the limestone formations of a large area of Europe and was the first species to be grown for ornamental purposes. $B$. microphylla is the second most important species group after $B$. sempervirens but it has never been found in the wild. It may have originated from Korea, Japan, or China (2). B. sinica var. insularis, or Korean boxwood, is native to Korea and parts of China. Its availability as an ornamental and the number of its cultivars have been growing due to its tolerance to cold (2). The majority of boxwood plants grown in the United Kingdom and other European countries are forms of the European species $B$. sempervirens and the Asiatic $B$. microphylla, with an increasing popularity for cultivars of $B$. sinica var. insularis $(2,4)$. Some cultivars of these species are well adapted for hedge planting and trimming. It has never been clear if these species were particularly susceptible to $C$. buxicola or rather more likely to be affected because of their widespread use as ornamentals. There is no information available about the host range of the fungus or the susceptibility of other, lesserknown Buxus spp. to the disease. Therefore, the second aim of this study was to compare the susceptibility of these commonly grown boxwood species with other less-well-known Buxus spp. originating from more widespread geographical locations.

\section{MATERIALS AND METHODS}

Plant material. All plant material (Table 1) was donated by Langley Boxwood Nursery (Hampshire, UK).

Fungal isolates. $C$. buxicola isolates RHS 9934, RHS 9961, and RHS 2426 
were used for survival assays on boxwood leaves; isolates RHS PT25, RHS 30135, and RHS 30920 were used for the spore germination an mycelium growth inhibition experiments; and isolates RHS 47, RHS 1180, and RHS 2426 were used for all additional experiments. Single-spore cultures were maintained on potatodextrose agar (PDA; Oxoid, Basingstoke, $\mathrm{UK})$ at $25^{\circ} \mathrm{C}$ in the dark.

Fungicides. All the fungicides used were commercially available: azoxystrobin (Amistar; Syngenta Crop Protection UK Ltd, Cambridge, UK), carbendazim (Delsene 50 Flo; Nufarm UK, Belvedere, UK), chlorothalonil (Bravo 500; Syngenta Crop Protection UK Ltd., Cambridge, UK), copper oxychloride (Murphy Traditional Copper Fungicide; Levington Horticulture Ltd., Ipswich, UK), kresoxim-methyl (Stroby WG; BASF, Cheadle Hulme, UK), mancozeb (Dithane 945; Bayer CropScience Ltd., Cambridge, UK), myclobutanil (Systhane; Bayer CropScience Ltd.), penconazole (Fungus Clear; The Scotts Company Ltd., Godalming, UK), prochloraz (Scotts Octave; Scotts, Ipswich, UK), boscalid + pyraclostrobin (Signum; BASF), epoxiconazole + pyraclostrobin (Opera; BASF), and epoxiconazole + kresoxim-methyl + pyraclostrobin (Opponent; BASF).

Mycelial growth inhibition. Mycelial plugs (about $3 \mathrm{~mm}$ in diameter) from 7day-old cultures were transferred to PDA plates amended with the various fungicides after autoclaving. The effects of the fungicides were tested on mycelial growth at concentrations of $0.001,0.005,0.01,0.05$, $0.1,0.2,0.5,1,2,5,10,20$, and $50 \mu \mathrm{g}$ a.i./ml. For the combined fungicides, the concentrations were calculated in reference to pyraclostrobin. Therefore, for pyraclostrobin at $1 \mu \mathrm{g}$ a.i./ml, boscalid was at $4 \mu \mathrm{g}$ a.i./ml in Signum, epoxiconazole was at $0.38 \mu \mathrm{g}$ a.i./ml in Opera, and epoxiconazole was at $0.38 \mu \mathrm{g}$ a.i./ml + kresoximmethyl was at $0.5 \mu \mathrm{g}$ a.i. $/ \mathrm{ml}$ in Opponent.

Each experiment was repeated once and all isolates were tested and replicated twice. The control plates did not include any fungicides. Fungal growth was as- sessed by measuring colony diameter in two directions at right angles 2, 7, and 14 days post inoculation.

Inhibition of the germination of conidia. Conidia suspensions of C. buxicola were prepared as follows. Several mycelial plugs from 7-day-old cultures were placed onto carnation leaf agar (11) and incubated at $25^{\circ} \mathrm{C}$ under near-ultraviolet light until sporulation was observed, usually after 7 to 10 days. The suspension was made by adding $3 \mathrm{ml}$ of sterile distilled water and a few drops of Tween 20 to the culture. The number of conidia was counted with a hemacytometer. PDA plates amended after autoclaving with the various fungicides were spread using a sterile glass rod with a $100-\mu$ l spore suspension at $10^{5}$ to $10^{6}$ conidia/ml.

The effects of all the fungicides on the conidia germination rate were assessed at concentrations of $0.001,0.005,0.01,0.05$, $0.1,0.2,0.5,1,2,5,10,20$, and $50 \mu \mathrm{g}$ a.i./ml. For the combined fungicides, the concentrations were calculated in reference to pyraclostrobin as for the mycelium growth inhibition experiment.

Each experiment was repeated once and all isolates were tested and replicated twice. Control plates did not include fungicides. A conidium was considered germinated when the germ tube length exceeded its width (22). The conidia germination rates were calculated after overnight incubation of the plates in the dark at $25^{\circ} \mathrm{C}$. At least 100 conidia arbitrarily chosen were counted per plate.

Pathogenicity assays. Detached stems with at least five leaves were taken from 11 species and cultivars of Buxus and Sarcococca. The assays were performed at least 6 months after apparently healthy plants were acquired to avoid any interference from possible fungicide applications at the nursery.

Infection of the plant material was achieved by dipping stems and leaves into a conidia suspension $\left(10^{6}\right.$ conidia/ml $)$ of $C$. buxicola. After a short drying period (e.g., $10 \mathrm{~min})$, the stems were dipped a second time. Two detached stems were inoculated per isolate (RHS 47, 1180, and 2426) and

Table 1. Plant material used in this study

\begin{tabular}{ll}
\hline Plant species & Geographical origin \\
\hline Buxus balearica & Mediterranean countries \\
B. bodinieri & China \\
B. glomerata 'Green Gem' & Cuba \\
B. harlandii & China \\
B. microphylla var. japonica 'National' & Japan \\
B. macowanii & South Africa \\
B. microphylla 'Faulkner' & Asia \\
B. riparia & Japan \\
B. sempervirens & Europe \\
B. sempervirens 'Suffruticosa' & Europe \\
B. sinica var. insularis & Korea and China \\
Sarcococca sp. & Asia \\
\hline
\end{tabular}

${ }^{y}$ Although native to China, the cultivated form appears not to be the true species. It is possibly a form of B. microphylla var. sinica of unknown origin.

${ }^{\mathrm{z}}$ B. microphylla was never found in the wild but possibly originated from Korea, Japan, or China (2). then placed on a damp water-absorbent mat in a propagator (Homebase, UK). This experiment was repeated three times. Propagators were placed in a glasshouse under natural light and a temperature range of 10 to $25^{\circ} \mathrm{C}$.

To monitor disease development on the different plant species, levels of infection and sporulation of each isolate were calculated. The infection level was determined by visually assessing the percentage of leaf spotting using the following scale: $0=0 \%$, $1=0$ to $25 \%, 2=25$ to $50 \%, 3=50$ to $75 \%$, and $4=75$ to $100 \%$. The same five leaves were assessed 3, 6, 10, and 12 days post infection.

The level of sporulation was assessed by submerging five assessed leaves of each infected plant species in a 50-ml centrifuge tube containing sterile distilled water supplemented with Tween $20(0.01 \% \mathrm{vol} / \mathrm{vol})$. After shaking for $15 \mathrm{~min}$ at room temperature, the leaves were removed. The conidia were centrifuged at 4,000 rpm for $5 \mathrm{~min}$ and resuspended in $1 \mathrm{ml}$ of sterile distilled water. The number of conidia was calculated by counting at three separate occasions with a hemacytometer. The leaf surface of each plant species was measured using the Delta-T Image Analysis System Dias II (Cambridge, UK). The number of conidia per square millimeter of leaf area was calculated.

Light microscopic observations. Three isolates (RHS 47, 1180, and 2426) were grown on carnation leaf agar (11) but only RHS 47 and 2426 sporulated. Single conidia suspensions $\left(5 \times 10^{5}\right.$ to $\left.10^{6} / \mathrm{ml}\right)$ of isolates RHS 47 and 2426 were used to inoculate detached shoots of $B$. sempervirens 'Suffruticosa' bearing at least five leaves. The infected shoots were placed on a wet mat in a propagator and incubated in a heated glasshouse under natural light. The maximum glasshouse temperature during the experiment was $19^{\circ} \mathrm{C}$ during the day and the minimum was $17^{\circ} \mathrm{C}$ at night. A minimum of five leaves per shoot were observed at $3,5,7$, and $24 \mathrm{~h}$ and every 24 $\mathrm{h}$ thereafter for 12 days post inoculation. At each time point, two shoots per isolate were stained according to Bruzzese and Hasan (8). After a brief rinse in water, the leaves were mounted in $50 \%$ glycerol and examined using a Leica compound microscope at low magnification. The percentage of germinated conidia was calculated and the extent of germ tube development was observed on the upper and lower leaf surfaces.

Survival of $C$. buxicola on boxwood leaves. Three different conidia suspensions were made from isolates RHS 9934, 9961, and 2426 (13) at a concentration of $10^{6}$ conidia/ml. These were bulked and $B$. sempervirens 'Suffruticosa' was inoculated. After 7 days of incubation, the leaves were fully colonized and the fungus sporulated abundantly. Nylon net bags, each containing five infected leaves, were 
placed on the surface of a tray of loamy soil or buried in a tray of loamy soil at a depth of $5 \mathrm{~cm}$. The trays were left outside from 21 June 2001 onward. The infected leaves in one bag were checked for viability of $C$. buxicola after 3 months, 6 months, and every month thereafter for 5 years. Because the leaves could not be differentiated from each other due to their decomposition, each bag of leaves was assessed as "viable" or "nonviable." The fungus was reisolated on potato carrot agar (PCA; carrot at $20 \mathrm{~g} / \mathrm{liter}$, potato at 20 g/liter, and Agar Technical Oxoid at 20 g/liter) amended with antibiotics (ampicillin at $30 \mu \mathrm{g} / \mathrm{ml}$ and streptomycin sulfate at $133 \mu \mathrm{g} / \mathrm{ml})$.

Statistical analysis. To calculate the effective concentration at which mycelial growth was inhibited by $50 \%\left(\mathrm{EC}_{50}\right)$, the mean daily optimum growth rate at each concentration for each isolate-fungicide combination was divided by the mean of its maximum growth rate. The maximum daily growth rate was usually the growth rate of the control or occasionally the growth rate taken at the minimum fungicide concentration $(0.001$ or $0.005 \mu \mathrm{g}$ a.i./ml). Therefore, the ratios of growth rate inhibition were restricted between 0 and 1 and considered as a pseudobinomial variable. The program PROC GLIMMIX in SAS was used to fit a generalized linear mixed model (glmm) with a logit link function and a binomial error distribution for each isolate-fungicide combination. The binomial error distribution takes into account the difference in variance across the ratios of growth rate inhibition. For each isolate-fungicide combination, the inhibition ratios were modeled against the $\log$ transformation of the fungicide concentration and an $\mathrm{EC}_{50}$ and $95 \%$ confidence interval was calculated using Fieller's theorem.

For the conidia germination inhibition experiment, all data were initially expressed as a ratio of germinated conidia to total number of conidia. Then, for each isolate-fungicide combination, the ratio was divided by the maximum germination rate to provide the "relative conidia germination rate." To calculate the effective concentration at which $50 \%$ of conidia germination was inhibited $\left(\mathrm{EC}_{50}\right)$, the same modeling procedure used for the mycelial growth inhibition was applied.

The effects of plant species, isolate, and experiment number on the susceptibility to leaf spotting were analyzed by General Estimating Equations (GEE). These models provide a method of analyzing correlated data, in this case a time series, which has been recorded using an ordinal scale. To summarize the differences between the 12 plant species and 3 isolates, the proportion of $50 \%$ leaf spotting was calculated at $3,6,10$, and 12 days.

In our study, an independent correlation structure was applied to the multinomial leaf data and modeled using the cumulative logit link function.

For the washing of conidia, the analysis was $\log$ transformed to equate variances between plant species' conidia concentrations. A general linear model was used to test the effects of host species and a least significant difference test (LSD) applied to identify the apparent grouping of the species.

The effects of isolate and leaf surface on the proportion of germinating conidia were tested by fitting a generalized linear mixed model (glmm) with logit link function and binomial error distribution. Leaf surfaces were treated as random effects. Numbers of conidia were analyzed by fitting a glmm using a log link function and poisson error distribution to model the count data.

\section{RESULTS}

Inhibition of mycelial growth. Only copper did not reduce mycelium growth to a level where $\mathrm{EC}_{50}$ values could be estimated. The most effective fungicides, based on the concentrations that inhibited $50 \%$ of growth, were carbendazim, pro- chloraz, kresoxim-methyl, penconazole, epoxiconazole + pyraclostrobin, and epoxiconazole + kresoxim-methyl + pyraclostrobin (Table 2). Some fungicides proved highly effective at inhibiting mycelial growth $100 \%$ up to 14 days; this was consistent across the three isolates tested. These were carbendazim (at $5 \mu \mathrm{g}$ a.i./ml), penconazole (at $2 \mu \mathrm{g}$ a.i. $/ \mathrm{ml}$ ), prochloraz (at $1 \mu \mathrm{g}$ a.i./ml), kresoxim-methyl (at $20 \mu \mathrm{g}$ a.i./ml), epoxiconazole + pyraclostrobin (at $1 \mu \mathrm{g}$ a.i./ml), epoxiconazole + kresoximmethyl + pyraclostrobin (at $10 \mu \mathrm{g}$ a.i./ml), and boscalid + pyraclostrobin (at $50 \mu \mathrm{g}$ a.i./ml).

Inhibition of the germination of conidia. The results of the assays are presented in Table 3. The fungicides based on copper, carbendazim, myclobutanil, penconazole, and prochloraz had little or no effect on conidia germination; therefore, their $\mathrm{EC}_{50}$ values could not be calculated. The fungicides azoxystrobin, chlorothalonil, kresoxim-methyl, mancozeb, boscalid + pyraclostrobin, epoxiconazole + pyraclostrobin, and epoxiconazole + kresoximmethyl + pyraclostrobin were highly effec-

Table 2. Inhibition of mycelial growth

\begin{tabular}{lccc}
\hline & \multicolumn{3}{c}{$\mathbf{E C}_{\mathbf{5 0}}(\mathbf{9 5 \%} \mathbf{C I})^{\mathbf{z}}$} \\
\cline { 2 - 4 } Fungicide & $\mathbf{3 0 1 3 5}$ & $\mathbf{3 0 9 2 0}$ & $\mathbf{P T 2 5}$ \\
\hline Azoxystrobin & $0.40(0.08-1.89)$ & $0.35(0.11-1.02)$ & $1.65(1.20-2.27)$ \\
Carbendazim & $0.14(0.04-0.32)$ & $0.02(0.01-0.05)$ & $0.47(0.05-3.33)$ \\
Chlorothalonil & $0.65(0.23-1.91)$ & $0.72(0.39-1.39)$ & $2.48(1.25-5.65)$ \\
Copper oxychloride & $\mathrm{NA}$ & $\mathrm{NA}$ & $\mathrm{NA}$ \\
Kresoxim-methyl & $0.03(0.01-0.07)$ & $0.03(0.01-0.05)$ & $0.09(0.03-0.18)$ \\
Mancozeb & $2.21(0.19-8.69)$ & $1.19(0.41-4.10)$ & $2.70(1.85-4.00)$ \\
Myclobutanil & $0.41(0.03-3.53)$ & $0.41(0.35-0.48)$ & $0.50(0.44-0.57)$ \\
Penconazole & $0.10(0.01-0.61)$ & $0.04(0.01-0.24)$ & $0.07(0.06-0.08)$ \\
Prochloraz & $0.02(0.01-0.03)$ & $0.01(0.01-0.02)$ & $0.03(0.02-0.05)$ \\
Boscalid + pyraclostrobin & $0.23(0.09-0.56)$ & $0.39(0.09-1.44)$ & $0.33(0.17-0.62)$ \\
Epoxiconazole + pyraclostrobin & $0.09(0.07-0.12)$ & $0.03(0.02-0.05)$ & $0.10(0.09-0.12)$ \\
Epoxiconazole + kresoxim-methyl & & & \\
+ pyraclostrobin & $0.04(0.02-0.10)$ & $0.02(0.01-0.04)$ & $0.17(0.14-0.21)$ \\
\hline
\end{tabular}

${ }^{z}$ Values $(\mu \mathrm{g}$ a.i./ml) for the effective concentration at which mycelial growth was inhibited by $50 \%$ $\left(\mathrm{EC}_{50}\right)$ with their $95 \%$ confidence intervals $(\mathrm{CI})$ for each isolate-fungicide combination; NA indicates that $\mathrm{EC}_{50}$ was not calculated for fungicides that did not inhibit mycelium growth (maximum concentration tested $=50 \mu \mathrm{g}$ a.i. $/ \mathrm{ml})$.

Table 3. Inhibition of conidia germination

\begin{tabular}{lccc}
\hline & \multicolumn{3}{c}{$\mathbf{E C}_{\mathbf{5 0}}(\mathbf{9 5 \%} \mathbf{C I})^{\mathbf{z}}$} \\
\cline { 2 - 4 } Fungicide & $\mathbf{3 0 1 3 5}$ & $\mathbf{3 0 9 2 0}$ & $\mathbf{P T 2 5}$ \\
\hline Azoxystrobin & $2.54(1.56-4.39)$ & $2.01(1.63-2.48)$ & $2.39(1.43-3.94)$ \\
Carbendazim & $\mathrm{NA}$ & $\mathrm{NA}$ & $\mathrm{NA}$ \\
Chlorothalonil & $0.36(0.13-0.90)$ & $0.53(0.15-1.78)$ & $0.44(0.17-1.09)$ \\
Copper oxychloride & $\mathrm{NA}$ & $\mathrm{NA}$ & $\mathrm{NA}$ \\
Kresoxim-methyl & $0.03(0.02-0.05)$ & $0.04(0.02-0.07)$ & $0.07(0.03-0.13)$ \\
Mancozeb & $0.41(0.13-1.26)$ & $0.35(0.14-0.80)$ & $0.70(0.23-2.05)$ \\
Myclobutanil & $\mathrm{NA}$ & $\mathrm{NA}$ & $\mathrm{NA}$ \\
Penconazole & $\mathrm{NA}$ & $\mathrm{NA}$ & $\mathrm{NA}$ \\
Prochloraz & $\mathrm{NA}$ & $\mathrm{NA}$ & $\mathrm{NA}$ \\
Boscalid + pyraclostrobin & $0.12(0.07-0.19)$ & $0.11(0.06-0.21)$ & $0.23(0.10-0.49)$ \\
Epoxiconazole + pyraclostrobin & $0.14(0.05-0.36)$ & $0.14(0.03-0.48)$ & $0.21(0.04-0.81)$ \\
Epoxiconazole + kresoxim-methyl & & & \\
+ pyraclostrobin & $0.10(0.04-0.24)$ & $0.12(0.02-0.04)$ & $0.16(0.06-0.36)$ \\
\hline
\end{tabular}

${ }^{\mathrm{z}}$ Value for the effective concentration at which mycelial growth was inhibited by $50 \%\left(\mathrm{EC}_{50}\right)$ values with their 95\% confidence intervals $(\mathrm{CI})$ for each isolate-fungicide combination; NA indicates that $\mathrm{EC}_{50}$ was not calculated for fungicides that did not reduce spore germination (maximum concentration tested $50 \mu \mathrm{g}$ a.i. $/ \mathrm{ml})$. 
tive, inhibiting at least $50 \%$ of the conidia germination at low fungicide concentrations. At higher concentrations, these fungicides also inhibited conidia germination by at least $90 \%$ and chlorothalonil caused $100 \%$ inhibition (results not shown). Results were consistent across the three isolates.
Light microscopic observations. Both isolates (RHS 47 and 2426) started germinating $3 \mathrm{~h}$ after inoculation (Fig. 1A). There were no significant effects due to upper or lower leaf surface over time, between isolates, or their interaction. Therefore, the hypothesis that the lower and upper surfaces have equal effects on the germination of conidia was accepted and data for the two surfaces were combined. Germination of isolate 2426 was significantly slower than isolate 47 at $5 \mathrm{~h}(P=$ $0.002)$ and $7 \mathrm{~h}(P=0.02)$. Isolate 2426 germination rate equaled that of isolate 47 after 1 day and, subsequently, no significant differences were recorded after that
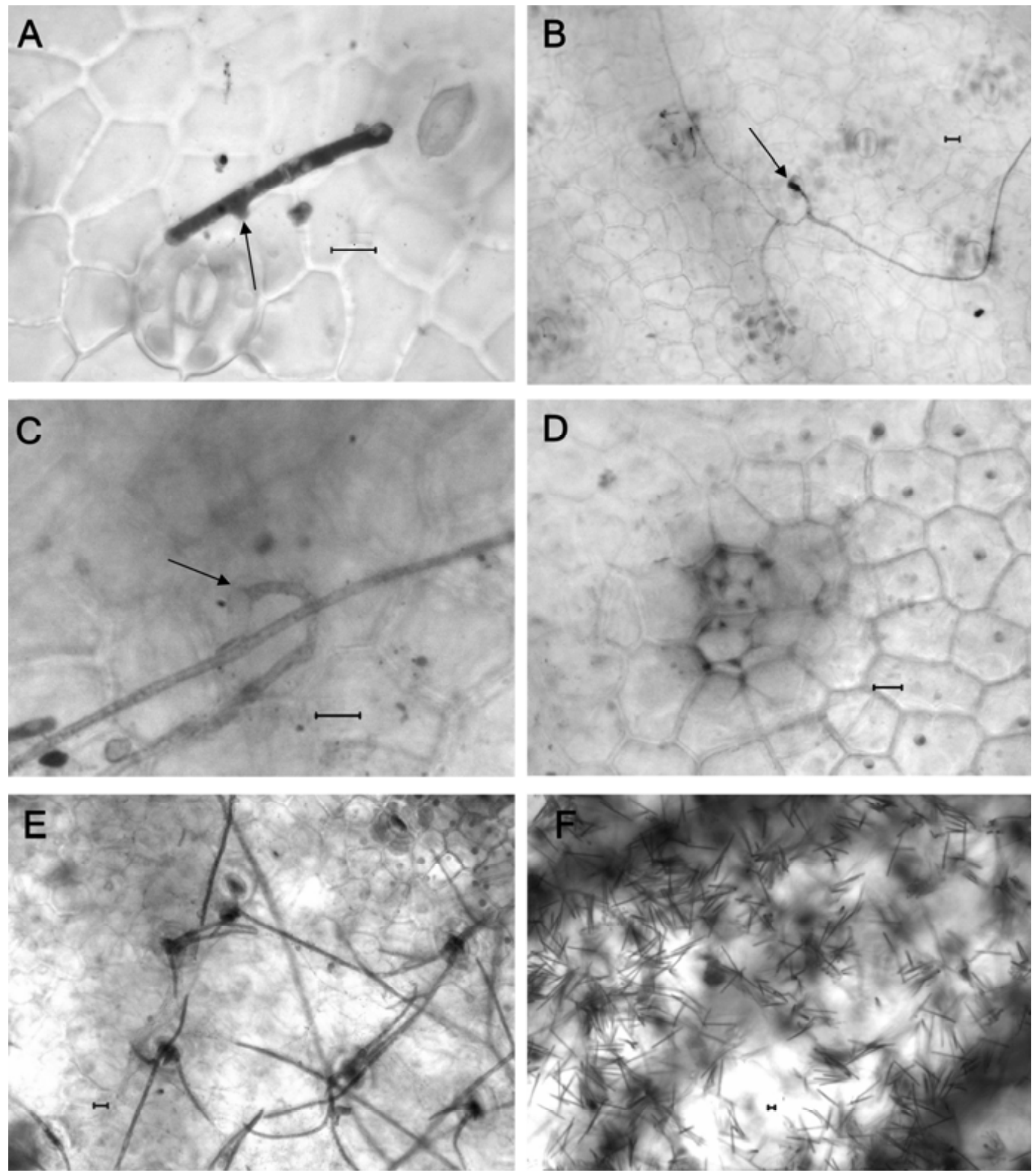

Fig. 1. Infection cycle of Cylindrocladium buxicola (isolate 47) on Buxus sempervirens 'Suffruticosa.' A, Conidia germination 3 h post inoculation (hpi) (arrow indicates point of germination); B, penetration of stoma 1 day post inoculation (dpi); $\mathbf{C}$, direct penetration of cuticle 5 hpi (point of entry indicated by arrow); D, intercellular growth (stained in blue) in mesophyll layer 4 dpi; $\mathbf{E}$, emergence through stomata 5 dpi; and $\mathbf{F}$, sporulation on the lower leaf surface 7 dpi. Bar $=10 \mu \mathrm{m}$. 
time (Fig. 2). Although there were no significant differences in the percentage of conidia germination between both surfaces, the upper surface retained a significantly higher number of conidia at all time periods $(P<0.001)$ and a significantly higher number of conidia of the isolate 47 was observed compared with isolate 2426 $(P<0.05)$ at 5,7 , and $24 \mathrm{~h}$.

Penetration occurred through stomata on the lower surface of the leaves and was observed 1 day after inoculation. No directional growth was seen by runner hyphae toward stomata; noticeably, hyphae had grown over or around stomata without entering (Fig. 1B). Penetration on the upper surface was not clearly observed, although penetration through the cuticle was seen $5 \mathrm{~h}$ post infection (Fig. 1C). Hyphae penetrated directly or by means of a side branch, without the formation of an appressorium. After penetration, fungal growth inside the leaf was not clearly seen; however, mycelium occasionally was observed growing intercellularly in the mesophyll cells (Fig. 1D). Resurgence of the hyphae occurred exclusively on the lower leaf surface through the stomata, starting 3 days after infection in both isolates (Fig. 1E). At 5 days after inoculation, large areas showed resurgence and, after 7 days, production of conidia was clearly visible (Fig. 1F).

Survival on decomposing boxwood material. Five years after infection, sporulation of the fungus on PCA was still possible. The fungus was able to survive equally on decomposing leaves left on the topsoil or on those buried in the soil. The fungus was recovered at all data collection points. There was no obvious development of microsclerotia on the remains of the leaves 5 years after infection.

Pathogenicity assays. The infection assays showed that none of the boxwood species tested were immune to C. buxicola. All the plants started showing foliar symptoms 3 days after inoculation. The grouping of the boxwood species and the related plant genus Sarcococca with similar susceptibility rates using a LSD test remained constant over time; therefore, only data showing the amount of foliar spotting at 6 days are shown (Table 4). There were some significant differences observed in the amount of leaf spotting among the different boxwood species but these were not completely consistent across the three fungal isolates. B. balearica, B. riparia, and Sarcococca sp. consistently showed the least-pronounced leaf symptoms. On the other hand, the worst affected species were $B$. sempervirens 'Suffruticosa' and $B$. sinica var. insularis. After 12 days, the conidia were washed from the infected leaves to assess whether there were significant differences in the amount of sporulation supported by different boxwood species and Sarcococca sp. (Fig. 3). Although $B$. riparia showed less severe leaf symp- toms, sporulation on this species was not consistently lower than on other boxwood species. The highest sporulation occurred on $B$. sempervirens and $B$. sempervirens 'Suffruticosa' and was significantly greater than that observed on B. balearica and Sarcococca sp. With isolates 1180 and 2426, sporulation on $B$. balearica was significantly lower than all the other boxwood species. However, with isolate 47, there were no significant differences in the amounts of sporulation occurring among B. balearica, B. japonica 'National,' $B$. microphylla 'Faulkner,' and B. riparia.

\section{DISCUSSION}

Before attempting to control boxwood blight in the field, preliminary in vitro experiments are useful to select fungicides that show inhibitory action on the mycelial growth and conidia germination. Mycelial growth of $C$. buxicola was more sensitive to the systemic fungicides than to the protectants. Indeed, the protectant fungicides copper oxychloride had no effect on mycelial growth. Mancozeb and chlorothalonil had generally higher $\mathrm{EC}_{50}$ values than systemic fungicides. Chlorothalonil was reported to be a very effective protectant and even eradicant of the fungus (Karel Goossens, personal communication). It inactivates sulfur-containing enzymes and, thus, disrupts energy production by the fungus (15). Chlorothalonil is considered to be mainly active against spore germination and, in our tests, $100 \%$ inhibition was observed. Additionally, we found that the $\mathrm{EC}_{50}$ values for the mycelium growth and spore germination inhibition were similar.

The fungicides that inhibit sterol biosynthesis such as prochloraz, penconazole, and myclobutanil are not usually used to inhibit spore germination, which relies on stored products and, therefore, can proceed in the absence of biosynthesis (15). This was supported in the assays where it was found that myclobutanil, penconazole, and prochloraz had no effect on conidia germination.

Carbendazim is a benzimidazole fungicide that disrupts mitosis during cell division, therefore inhibiting the development of germ tubes and mycelial growth. In our assays, although the germination rate was not affected by carbendazim, the subsequent growth of the germ tubes (data not shown) and the mycelial growth were impaired as shown by the low $\mathrm{EC}_{50}$ values obtained for all isolates.

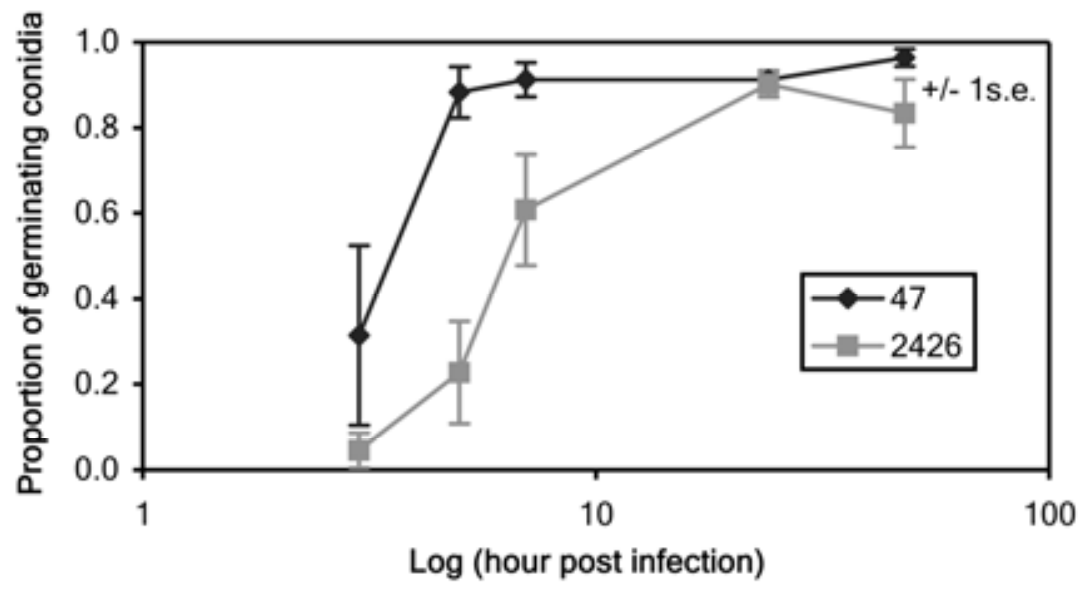

Fig. 2. Proportion of germinated conidia, over time, of Cylindrocladium buxicola isolates 47 and 2426 (vertical bars indicate standard errors [se]) on leaf surfaces of Buxus sempervirens 'Suffruticosa.'

Table 4. Estimated proportion of boxwood and Sarcococca leaves with greater than 50\% spotting at day 6 for each boxwood species and isolate averaged over the three experiments

\begin{tabular}{|c|c|c|c|}
\hline \multirow[b]{2}{*}{ Host species } & \multicolumn{3}{|c|}{ Proportion of leaves with $>50 \%$ spotting $z$} \\
\hline & Isolate 47 & Isolate 2426 & Isolate 1180 \\
\hline Buxus balearica & $0.03 \mathrm{a}$ & $0.10 \mathrm{a}$ & $0.05 \mathrm{a}$ \\
\hline B. riparia & $0.06 \mathrm{ab}$ & $0.17 \mathrm{ab}$ & $0.10 \mathrm{ab}$ \\
\hline Sarcococca sp. & $0.09 \mathrm{bc}$ & $0.08 \mathrm{a}$ & $0.13 \mathrm{abc}$ \\
\hline B. microphylla 'Faulkner' & $0.11 \mathrm{bc}$ & $0.50 \mathrm{~cd}$ & $0.22 \mathrm{bcd}$ \\
\hline B. bodinieri & $0.13 \mathrm{bcd}$ & $0.38 \mathrm{c}$ & 0.46 ef \\
\hline B. microphylla var. japonica & $0.15 \mathrm{bcd}$ & $0.32 \mathrm{bc}$ & $0.14 \mathrm{bc}$ \\
\hline B. glomerata 'Green Gem' & 0.23 cde & $0.40 \mathrm{c}$ & $0.37 \mathrm{def}$ \\
\hline B. sempervirens & $0.28 \mathrm{def}$ & 0.56 cde & 0.26 cde \\
\hline B. harlandii & 0.45 efg & $0.48 \mathrm{~cd}$ & 0.34 def \\
\hline B. macowanii & 0.48 efg & $0.49 \mathrm{~cd}$ & $0.38 \mathrm{def}$ \\
\hline B. sempervirens 'Suffruticosa' & $0.50 \mathrm{fg}$ & $0.75 \mathrm{e}$ & $0.57 \mathrm{f}$ \\
\hline B. sinica var. insularis & $0.70 \mathrm{~g}$ & $0.68 \mathrm{de}$ & $0.55 \mathrm{f}$ \\
\hline
\end{tabular}

z Values within isolates (columns) followed by different letters have a significantly different susceptibility rate using a least significance difference test $(P=0.05)$. Letters can be compared only within isolates (columns). 

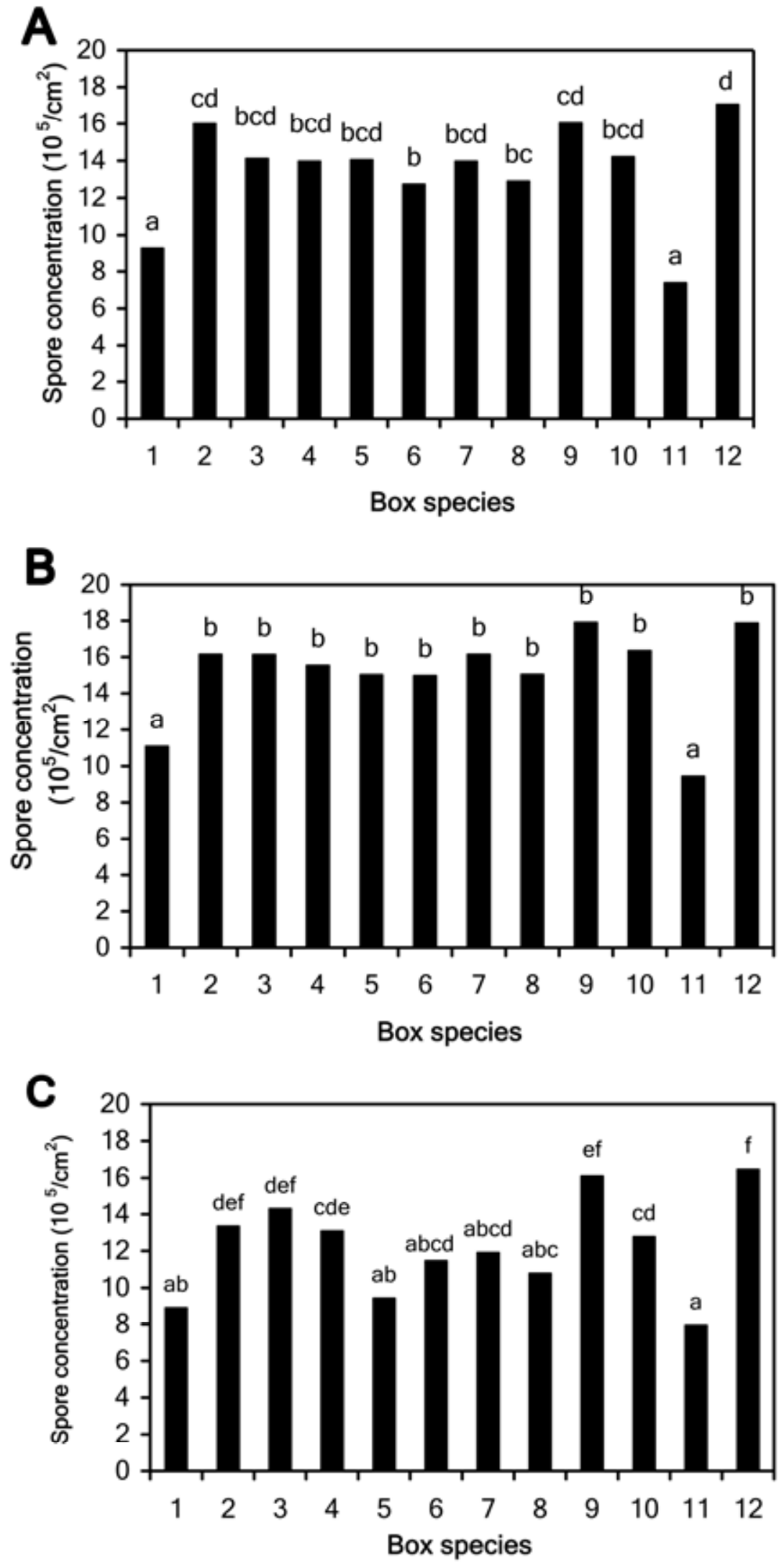

Fig. 3. Conidia concentration of the isolates A, 1180; B, 2426; and C, 47 on the boxwood species and Sarcococca sp. 12 days post inoculation. Boxwood species and Sarcococca sp. are indicated on the X axis as $1=$ Buxus balearica, $2=B$. bodinieri, $3=B$. glomerata 'Green Gem', $4=B$. harlandii, $5=B$. japonica 'National', $6=B$. macowanii, $7=B$. microphylla 'Faulkner', $8=B$. riparia, $9=B$. sempervirens, $10=B$. sinica var. insularis, $11=$ Sarcococca sp., and $12=B$. sempervirens 'Suffruticosa'. Letters have been calculated using a least significance test and highlight boxwood species that have a significantly different susceptibility rate at $95 \%$ level of significance. Letters can be compared only within isolates.
The strobilurin fungicide class, including azoxystrobin and kresoxim-methyl, is a recent group of fungicides which block mitochondrial respiration in fungi by inhibiting the cytochrome bc1 enzyme complex at the Qo site in the respiration chain of fungal mitochondria (QoI inhibitors) (1). Of the two, kresoxim-methyl appeared to be the most effective fungicide, having a very low $\mathrm{EC}_{50}$ for mycelial growth and conidia germination for the three isolates tested. The fungicides Opera (epoxiconazole + pyraclostrobin) and Opponent (epoxiconazole + kresoxim-methyl + pyraclostrobin), with their combination of active ingredients, were highly effective in inhibiting mycelial growth and conidia germination with similarly low $\mathrm{EC}_{50}$ values. Both pyraclostrobin and kresoximmethyl belong to the strobilurin class of fungicides; however, the presence of kresoxim-methyl in Opponent did not affect the $\mathrm{EC}_{50}$ for the mycelium inhibition and spore germination compared with Opera. This means that Opera could be a useful replacement to Opponent because, at the time of writing this article, Opponent is not longer to be sold by BASF due to the low demand of this product (Robert Storer, personal communication).

Boscalid is a carboxamide fungicide which inhibits the enzyme succinate ubiquinone reductase (complex II) in the mitochondrial electron transport chain. It disrupts fungal growth by preventing energy production and by eliminating the availability of components of the tricarboxylic acid cycle for the synthesis of amino acids and lipids (26). Its use with the strobilurin fungicide pyraclostrobin was usually less effective in inhibiting mycelial growth than in inhibiting spore germination. It has been reported that spore germination is a developmental stage more sensitive to strobilurins and boscalid than mycelium growth in fungi such as Botrytis cinerea and Neurospora crassa $(23,26)$.

These in vitro assays identified several fungicides effective against $C$. buxicola. These were kresoxim-methyl and the combined fungicides Opponent (epoxiconazole + kresoxim-methyl + pyraclostrobin), Opera (epoxiconazole + pyraclostrobin), and Signum (boscalid + pyraclostrobin). Field trials are now in progress to test the efficacy of these fungicides in vivo.

It is essential to understand the epidemiology of a disease before attempting to control it using a mixture of chemical and cultural methods. Pathogenicity tests in this study showed that there were no boxwood species immune to C. buxicola. In addition, a new genus, Sarcococca, was found to be a potential host for the disease. Sarcococca is in the family Buxaceae and is grown as ground cover or for informal hedging but has never been found naturally infected. It would be interesting to know if other genera in the family Buxaceae, such as Pachysandra, are also susceptible. 
Within the genus Buxus only the species sempervirens, microphylla, and sinica have so far been reported as hosts for the disease. The experiments showed that the host range within the genus could be quite extensive, including the species balearica, bodinieri, glomerata, harlandii, macowanii, and riparia. All these species occur naturally over four continents (35,9; Table 1). Therefore, the consequences could be dramatic if the disease was accidentally introduced to their native regions.

Even though the species tested originated from geographically isolated parts of the world, none of them was found to be immune to the pathogen. However, there were some significant differences in the expression of the symptoms and the amount of conidia produced at the end of the cycle. In the genus Buxus, Buxus balearica appeared to be the most resistant plant species, probably due to the texture of the leaves. These are very thick, leathery, and coriaceous (2) and could be a disadvantage to a fungus that penetrates directly through the cuticle. Correlation between cuticle thickness and disease resistance has been reported in several plantfungal pathosystems, including powdery mildew on rose (12) and grape (18), scab on peanut (10), the blast agent Pyricularia grisea on millet (17), and downy mildew on muskmelon (20). Also, the number of spores retained by the leaf could be lower and, as a result of fewer infection points (hence fewer points of emergence), there was less overall sporulation. Because the experiments were carried out on detached stems rather than whole plants, the pathogenicity assays did not test for any influence of the growth habit on disease development.

B. sempervirens 'Suffruticosa' has always been reported as the species most commonly affected by the disease. It has a compact growth habit (5), which helps retain water needed for conidia germination and infection. However, the pathogenicity assays showed it is more susceptible to infection than the other species tested regardless of growth habit. Other species with compact growth habits are $B$. sempervirens, $B$. microphylla, and $B$. sinica var. insularis, and this lends them to formal clipping and hedge making. However, this could increase their susceptibility to the disease, with wounding sites acting as possible entry points for conidia. Based on the symptoms observed, $B$. sinica var. insularis was significantly more susceptible than the other species, excluding $B$. sempervirens 'Suffruticosa'. Except for $B$. balearica and Sarcococca sp., the sporulation level on most species was high and not significantly different, indicating that a good nutritional relationship exists between the hosts and the parasite and that this relationship is maintained until the fungal reproduction is extensive. However, the low sporulation on B. balearica and Sarcococca sp. could contribute to field resistance and might explain why this disease has not been seen on these two hosts in field.

The qualitative and quantitative observations of the life cycle of the fungus showed that the life cycle is completed within a week. It is important to apply fungicides on both sides of the leaves to prevent germination and penetration. Microsclerotia have been observed in several species of Cylindrocladium and, for some of them, is the primary survival structure in soil $(16,19,25)$. For example, the conidia of $C$. crotalariae were not viable after 8 months on decomposing papaya tissues (16) while the microsclerotia survived for 3 years (21). During the 5-year experiment examining survival of the $C$. buxicola on decomposing material, no microsclerotia were observed. It appears that the fungus is able to survive within decomposing tissues as mycelium. Thus, the deposition of infected leaves on the soil surface due to defoliation would seem to be one important survival mechanism for $C$. buxicola. This observation is potentially critical for disease management, emphasizing the importance of removing the fallen material to reduce the level of infection. With the reduction of the number of available fungicides to amateur gardeners in the United Kingdom, cultural methods are sometimes the sole way of managing the disease.

\section{ACKNOWLEDGMENTS}

We thank A. Peace for his help with the statistical analyzes, R. Cook for his critical review of the manuscript, and Langley Boxwood Nursery for the donation of the plants.

\section{LITERATURE CITED}

1. Bartlett, D. W., Clough, J. M., Godwin, J. R., Hall, A. A., Hamer, M., and Parr-Dobrzanski, B. 2002. The strobilurin fungicides. Pest Manage. Sci. 58:649-662.

2. Batdorf, L. R. 2004. Boxwood: An Illustrated Encyclopedia. The American Boxwood Society, Boyce, VA.

3. Bean, W. J. 1970. Trees and Shrubs Hardy in the British Isles. M. Bean and J. Murray Ltd., London.

4. Bradley-Hole, K. 1997. All about box. Garden. Dec. issue. 854-859.

5. Braimbridge, E. 1994. Some boxwoods in cultivation. Plantsman 15(4):236-254.

6. Brand, T. 2005. Auftreten von Cylindrocladium buxicola B. Henricot an Buchsbaum in Nordwest-Deutschland. Nachrichtenbl. Dtsch. Pflanzenschutzdienst (Berlin) 57 (12):237-240.

7. Brasier, C. 2005. Preventing invasive pathogens: deficiencies in the system. Plantsman 4 (1):54-57.

8. Bruzzese, E., and Hasan, S. 1983. A whole leaf clearing and staining technique for host speci- ficity studies of rust fungi. Plant Pathol. 32:335-338.

9. Cullen, J., Alexander, J. C. M., Brickell, C. D., Edmondson, J. R., Green, P. S., Haywood, V. H., Jørgensen, P.-M., Jury, S. L., Knees, S. G., Matthews, V. A., Maxwell, H. S., Miller, D. M., Nelson, E. C., Robson, N. K. B., Walters, S. M., and Yeo, P. F. 1997. The European Garden Flora. Cambridge University Press, Cambridge.

10. Fang, S. M., Wang, Z. R., Ke, Y. Q., Chen, Y. S., Huang, C. M., and Yu, J. X. 2007. The evaluation of resistance and resistant mechanisms of peanut varieties to scab disease. Sci. Agric. Sin. 40:291-297.

11. Fisher, N. L., Burgess, L. W., Toussoun, T. A., and Nelson P. E. 1982. Carnation leaves as a substrate and for preserving cultures of Fusarium species. Phytopathology 72:151-153.

12. Heintz, C., and Blaich, R. 1989. Structural characters of epidermal walls and resistance to powdery mildew of different grapevine cultivars. Vitis 28:153-160.

13. Henricot, B., and Culham, A. 2002. Cylindrocladium buxicola, a new species affecting Buxus spp., and its phylogenetic status. Mycologia 94 (6):980-997.

14. Henricot, B., Pérez Sierra, A., and Prior, C. 2000. A new blight disease on Buxus in the UK caused by the fungus Cylindrocladium. Plant Pathol. 49:805.

15. Hewitt, H. G. 1998. Fungicides in Crop Protection. CAB International, Wallingford, UK.

16. Hwang, S. C., and Ko, W. H. 1976. Biology of conidia, ascospores, and microsclerotia of $\mathrm{Ca}$ lonectria crotalariae in soil. Phytopathology 66:51-54.

17. Kumar, V. B. S., and Kumar, T. B. A. 2006. Anatomical defence mechanism in finger millet leaves against blast caused by Pyricularia grisea Sacc. Mysore J. Agric. Sci. 40:27-30.

18. Mence, M. J., and Hildebrandt, A. C. 1966. Resistance to powdery mildew in rose. Ann. Appl. Biol. 58:309-321.

19. Morrison, R. H., and French, D. W. 1969. Direct isolation of Cylindrocladium floridanum from soil. Plant Dis. Rep. 53:367-369.

20. Prabhpreet, I., Dhillon, M., and Singh, P. P. 1999. Pre-penetration anatomical barriers of muskmelon leaf against downy mildew disease. Plant Dis. Res. 14:1-6.

21. Rowe, R. C., Beute, M. K., Wells, J. C., and Wynne, J. C. 1974. Incidence and control of Cylindrocladium black rot of peanuts in North Carolina during 1973. Plant Dis. Rep. 57:387389.

22. Sharma, J. K., and Mohanan, C. 1991. Pathogenic variation in Cylindrocladium quinque septatum causing leaf blight of Eucalyptus. Eur. J. For. Pathol. 21:210-217.

23. Stade, S., and Brambl, R. 1981. Mitochondrial biogenesis during fungal spore germination: respiration and cytochrome $c$ oxidase in Neurospora crassa. J. Bacteriol. 147 (3):757767.

24. Strouts, R. G., and Winter, T. G. 2000. Diagnosis of ill-health in trees. Forestry Commission. Research for Amenity Trees No. 2. HMSO, London.

25. Thies, W. G., and Patton, R. F. 1970. The biology of Cylindrocladium scoparium in Wisconsin forest tree nurseries. Phytopathology 60:1662-1668.

26. Zhang, C. Q., Yuan, S. K., Sun, H. Y., Qi, Z. Q., Zhou, M. G., and Zhu, G. N. 2007. Sensitivity of Botrytis cinerea from vegetable greenhouses to boscalid. Plant Pathol. 56:646653. 